\title{
Fontes de memória e o conceito de escrita videográfica: a propósito da fatura do texto videográfico Milton Guran em três tempos (LABHOI, 2010)*
}

\author{
Ana Maria Mauad**
}

O trabalho histórico com fontes de memória coloca ao historiador um desafio: operar ao mesmo tempo com uma fonte que é também objeto de análise. A fotografia, por exemplo, quando integrada às temáticas históricas, implica a redefinição das etapas heurísticas da pesquisa, orientando o trabalho de sistematização dos dados de forma a recuperar os caminhos pelos quais a imagem foi produzida, ganhou circulação e foi recebida e apropriada por diferentes grupos sociais. Cada tipo de fotografia possui um circuito social distinto associado, em grande medida, à agência que a produziu. Tal característica determina os demais textos, que interagem com a fotografia no processo contínuo de produção de sentido social.

Por outro lado, a própria narrativa histórica orientada pelo uso de fontes orais, quer como fonte de dados, ou como objeto de estudo (ou como os dois ao mesmo tempo), transforma-se, inserindo no seu discurso elementos do processo de rememoração.

* Este texto se insere no projeto de pesquisa "Imagens contemporâneas", com financiamento do CNPq, bolsa de produtividade 2008-2011 e apoiado pela Faperj com uma bolsa de apoio técnico (2007-2010), e pelo Edital Humanidades (2008-2010). Agradeço especialmente o apoio de Milton Guran, objeto de estudo e importante interlocutor de uma escrita da história com imagens.

** Professora associada do Departamento de História da Universidade Federal Fluminense (UFF), pesquisadora do Laboratório de História Oral e Imagem da UFF (LABHOI) e do CNPq. 
Nesse sentido, o uso de fontes orais e visuais na produção do texto histórico impõe ao historiador um outro desafio que, aos poucos, vai sendo enfrentado: o uso de outras linguagens para compor uma nova narrativa histórica que dê conta da dimensão intertextual estabelecida entre palavras e imagens.

O objetivo deste texto é refletir sobre tais questões com base no trabalho que o Laboratório de História Oral e Imagem da Universidade Federal Fluminense (LABHOI/UFF) desenvolve desde 1982, quando foi criado pelas historiadoras Ismênia Lima Martins e Eulália Lobo. Para tanto, proponho uma abordagem que se inicia com considerações sobre a relação entre prática historiadora e prática social, e na sequência apresenta a fatura do texto videográfico Milton Guran em três tempos, realizado em parceria com a cineasta Tarsila Pimentel.

I

O marco historiográfico que se constitui pela noção de história do tempo presente incorpora os temas colocados na pauta da contemporaneidade como objetos de reflexão, dentre os quais se destacam: a crise dos espaços legítimos de representação, a mundialização da cultura, a fragmentação dos sujeitos sociais, a redefinição dos espaços sociais de legitimação do político, as políticas de identidade e de memória, entre outros que devem ser adensados a partir de uma reflexão sobre as suas dinâmicas temporais de duração, ruptura e distanciamento.

No bojo da construção das dinâmicas temporais que definem a tessitura histórica do tempo presente, destaca-se a história da produção da memória social por diferentes agentes históricos que tiveram um papel significativo na elaboração dos quadros culturais de uma época, como uma das peças-chave para a estruturação do projeto de história que demarcam as pesquisas realizadas no âmbito do LABHOI.

A emergência do tema da memória se deu, no Brasil, em compasso com o processo de redemocratização da sociedade brasileira, associada às dimensões da memória dever e da necessidade de não esquecer. Esse fenômeno não se limita ao Brasil, e, no caso do Cone Sul, ao menos mais dois processos históricos evidenciam um movimento no mesmo sentido, o caso argentino e o caso chileno. O que aproxima o estudo da memória nesses três países, sem dúvida, foram os períodos autoritários e a forma como a sociedade civil 
se relaciona com eles. Não vou aprofundar esse estudo, mas o que quero ressaltar é o fato de que tanto no Brasil quanto na Argentina, mas com menos ênfase no Chile, as instituições universitárias assumem para si a tarefa de organizar esse processo de rememoração historicamente através do recurso à história oral. ${ }^{1}$

Basta acompanharmos os relatos nos encontros nacionais e internacionais de história oral para nos darmos conta de como as ciências sociais sulamericanas, ao longo dos anos 1990, encamparam a memória como tema de estudo. No caso da história, esse processo se dá de forma original e variada, alimentando-se em grande medida das experiências provenientes de campos sociais muito diferenciados. Estes campos englobam desde a história política, através dos relatos dos representantes das elites no poder, incorporando as tendências mais radicais da "história que vem de baixo", associadas aos movimentos baseados em comunidade como history workshops na Inglaterra e public history, nos Estados Unidos e demais países de língua inglesa; nesses casos as iniciativas de história oral partiram de iniciativas de agentes do poder político ou do movimento social. No entanto, a forma como o campo da história oral é organizado no Cone Sul, notadamente no Brasil, não tem paralelo nos países norte-americanos e europeus. Ressalta-se que no caso brasileiro as pesquisas universitárias e os projetos institucionais desenvolvidos no âmbito acadêmico tomaram a memória social como objeto de estudo.

Nos casos sul-americanos, voltados para a produção de uma narrativa sobre a história do tempo presente, inacessível pelos arquivos do poder, e para as propostas radicais associadas a uma história dos que fizeram, mas não escreveram, a história, a prática historiadora se confunde com a prática social. Isso porque se redefine o estatuto de objetividade científica através da produção de uma autoridade compartilhada entre sujeito e objeto do conhecimento, por dividirem e vivenciarem a mesma condição de sujeitos da experiência histórica. $\mathrm{O}$ que de fato se propõe nessa perspectiva de estudo é que a prática historiadora se alie à prática social na produção de um conhecimento compartilhado e reconhecido como válido pelos sujeitos históricos.

1 A bibliografia sobre o tema é extensa e variada; recomendo para uma visão de conjunto que se consultem os anais dos encontros de História Oral da Associação Brasileira de História Oral, bem como dos encontros internacionais da International Oral History Association. 
Nesse registro de história, é importante ressaltar, ninguém dá voz ao aos que não têm voz, não há resgate de memória, pois o que se produz é um novo tipo de conhecimento que supera o passado. Supera, no sentido de suspender, elevar a lembrança da experiência empírica vivida pelos seus agentes a uma nova forma de relato que a contém, processada e construída à luz de uma problemática de estudo.

Dentro dessa perspectiva se inscrevem os trabalhos desenvolvidos no LABHOI, por enfatizarem tanto a história da memória de grupos sociais ou de indivíduos como a lógica da produção e circulação das fontes visuais, orais e/ou escritas que se organizam para a produção do conhecimento histórico. Esse objetivo geral é implementado pelos pesquisadores do núcleo, ao se debruçarem em suas pesquisas sobre as múltiplas dimensões temporais da história na sua relação com a memória social.

Os projetos desenvolvidos no âmbito do LABHOI, além de compartilharem desse princípio teórico geral, se orientam segundo princípios metodológicos adequados à guarda, sistematização, disponibilização e análise dos dados de pesquisa com fontes visuais e orais, utilizando-se para tanto do conceito de intertextualidade. Tal princípio orienta-se tanto por uma dimensão hermenêutica - responsável pela ampliação do universo da interpretação histórica - quanto pela dimensão de prática social, sujeita a disputas e conflitos, próprios aos trabalhos de memória.

No primeiro caso, a noção de intertextualidade implica a concepção de que a textualidade (produção textual como produção de sentido) de um período é composta por diferentes tipos de textos que se condicionam entre si. Logo um texto só pode ser lido à luz de outros. No entanto, não se trata de uma justaposição de textos, mas fundamentalmente da tentativa de recuperar a substância significativa que fornece sentido ao entramado de imagens e palavras.

$\mathrm{Na}$ sua segunda dimensão, o conceito de intertextualidade compreende os textos históricos como campos de significação, resultantes de práticas sociais de produção sígnica, envolvendo um processo contínuo de disputa pelos sentidos socialmente aceitos como válidos. Portanto há que se considerar a lógica do relacionamento intertextual como sendo pautada pelas condições históricas dos sujeitos sociais produtores de textos/discursos. Assim, disputa e conflito social inscrevem-se na produção, circulação, consumo e, portanto, interpretação crítica dos textos sociais. 
Neste ponto, introduzo os princípios que orientam a prática metodológica desenvolvida pelo LABHOI para a composição de um texto historiográfico que inclua, na sua fatura, a relação entre palavras e imagens.

Em primeiro lugar, há que se precisar como essa relação se fundamenta no trabalho de pesquisa histórica. Assim, as fontes orais e visuais - fotográficas, fílmicas e pictóricas - tomadas como fontes de memória, associam-se aos processos de rememoração que criam narrativas sobre um determinado tempo e espaço passados. Nesse caso, a diferenciação do circuito de produção da fonte de memória é estabelecida pelo tipo de seu arquivamento.

No caso da fonte oral, ela é resultante de uma situação de entrevista onde pesquisador e entrevistado vivenciam um processo de construção de memórias mediante a uma negociação. Nessa negociação competem alguns aspectos que considero importante serem apontados: a competência do pesquisador que se apresenta como detentor de um saber consolidado e específico; a competência do entrevistado que detém o conhecimento da experiência vivida. A forma como essa situação se resolve na produção da fonte histórica está associada a um contrato social que define o espaço social da universidade como legitimadora da experiência histórica por um lado, e por outro, que reconhece a legitimidade da prática social como conhecimento histórico. Só a crença na legitimidade social dessas instâncias possibilitará a produção de um conhecimento intersubjetivo. Alguns elementos desse contrato merecem ser ressaltados:

1) Escuta: esse aspecto lida com a competência do entrevistador na situação da entrevista e a forma como opera com a noção de autoridade compartilhada (Frisch, 1990).

2) Argumentos e memórias: esse ponto compreende que todo o processo de rememoração envolve necessariamente a construção de argumentos, que definem sentido à história contada.

3) Narrativas: esse aspecto envolve os dois anteriores, pois é nele que se define a relação entre a escrita da história, ou a narrativa historiográfica, de competência do entrevistador/historiador, e a construção da memória social, através da narrativa biográfica, da competência do entrevistado. 
No caso da fonte visual, há que se estabelecer uma diferenciação: quando a fonte é produzida na pesquisa de campo, filmagens e fotografias que serão posteriormente relacionadas à situação das entrevistas num texto próprio; ou quando a fonte visual é proveniente de um arquivo privado ou público, e passa a integrar a pesquisa como fonte para o estudo dos comportamentos e representações sociais relativas às memórias de grupos sociais. No primeiro caso, o produto resultante da pesquisa definirá os usos e funçóes da imagem produzida; já no segundo, compete entender o circuito social da imagem analisada em termos de produção, circulação, consumo e seu agenciamento pela própria memória arquivística ou dos seus próprios produtores e guardiões.

Essa diferenciação orienta a forma como as fontes visuais interagem com as fontes orais nos diferentes trabalhos do LABHOI. Caberia aqui uma breve avaliação do uso comprobatório, ilustrativo, hermenêutico, ou ainda, iconológico ou semiótico das imagens visuais nos textos históricos, mas vou poupar o leitor dessa digressão. O que importa de fato para essa apresentação é indicar que a base da interação entre palavras e imagens no trabalho do LABHOI é a concepção de "texto videográfico". Um termo em grande medida criado para sairmos dos debates sobre documentário cinematográfico, e valorizarmos a necessidade de divulgar o trabalho acadêmico num suporte alternativo ao papel e com uma linguagem atualizada, bem como termos um produto que possa ser retornado ao entrevistado como resultado de um trabalho de produção de sentido (dentro dos protocolos da produção de fontes orais está previsto oferecer ao entrevistado uma forma de objetivação do tempo cedido na entrevista).

O uso das fontes visuais - pictórica, fílmica e fotográfica - pelo LABHOI integra hoje o que, em nossas discussões, denominamos de "a escrita videográfica". A "escrita videográfica" como resultado da pesquisa histórica implica a elaboração de um novo tipo de texto histórico que considere na sua produção a natureza do tipo de enunciação da fonte trabalhada. Assim, as fontes orais, visuais e sonoras para serem objeto de reflexão historiográfica e comporem o texto histórico devem ter sua substância de expressão preservada. As estratégias de elaboração dessa nova modalidade de escrita da história contam com a ampliação do diálogo entre conhecimento histórico e produção audiovisual, através do trabalho em pareceria de historiadores e profissionais de cinema. Um trabalho no qual cada um colabora com o seu conhecimento e experiência numa produção coletiva que congrega as competências individuais. 
Nesse sentido, o LABHOI vem investindo na elaboração de diferentes modalidades de produtos em vídeo que podem ser diferenciados em quatro tipos:

1) Escrita direta e interativa: a filmagem possui um roteiro estabelecido a partir de uma pesquisa acadêmica que não se baseou em fontes orais. $\mathrm{O}$ roteiro é feito com base na pesquisa histórica trazendo para a atualidade aspectos dessa pesquisa que ainda encontram-se como vestígios do passado.

2) Escrita intertextual: nessa modalidade o roteiro se baseia na estrutura da entrevista, organizada segundo o problema levantado pela pesquisa. A narrativa é composta por falas coordenadas retiradas de várias entrevistas; a essa polifonia são associadas imagens fixas operadas no programa de edição para ganharem movimento. Cada sequencia fílmica é composta por um conjunto de falas associadas a um conjunto de imagens que são apresentadas em movimento, garantindo o efeito fílmico.

3) Escrita intertextual ampliada: utiliza-se dos recursos do documentário cinematográfico interpolando imagens fixas filmadas, cenas filmadas em eventos ao vivo, cenas de entrevistas filmadas. Compóe a narrativa videográfica a música incidental, a trilha sonora, a leitura de depoimentos e a fala dos entrevistados.

4) Escrita videoclipe: sob inspiração da cultura dos videoclipes. Nesse caso específico, uma música da época serve de base para a composição de um texto breve de cerca de nove minutos, no qual as imagens fotográficas, dinamizadas por efeitos visuais, são associadas ao ritmo da música e intercaladas ou não com depoimentos sobre o acontecimento ou o tema em questão.

Em todos os casos o que distingue a forma de escrita videográfica é: o uso de ilha de edição digital, a transcrição digital das fontes orais e visuais, a forma de inserção do registro oral, o tempo da narrativa fílmica associado ao problema histórico tratado (processo, acontecimento, rememoração, etc.), e, por fim, a trama de palavras e imagens na construção do texto historiográfico.

Portanto, cria-se, com a "escrita videográfica", uma proposta de produzir conhecimento histórico, que envolve a articulação de diferentes substâncias significantes: visuais, verbais, sonoras, na busca de uma trama histórica que 
se alargue, multiplique e se identifique com seus sujeitos sociais, no passado e no presente. ${ }^{2}$

O trabalho Milton Guran em três tempos inscreve-se na segunda modalidade de texto videográfico, e foi resultado de uma parceria com a cineasta Tarsila Pimentel e de compartilhamento de experiências e conhecimento com Milton Guran, entre 2009 e 2010. O roteiro básico do texto videográfico foi montado com base em três entrevistas realizadas no âmbito do projeto de pesquisa "Imagens contemporâneas: prática fotográfica e os sentidos da história na imprensa ilustrada (1930-1970)”, já tratadas como fontes de pesquisa e depositadas nos arquivos do LABHOI, ${ }^{3}$ e mais uma entrevista em 2009, cujo roteiro se apoiava justamente nos três tempos da trajetória do fotógrafo, a saber: seu engajamento com o movimento das agências independentes, atuantes durante o processo de redemocratização da sociedade brasileira, no final dos anos 1970; sua atuação entre o final dos anos 1970 e meados da década de 1980, quando a questão indígena se define como questão nacional presente na Constituinte de 1988; e, por fim, como antropólogo em pesquisa de campo na África, para o estudo dos retornados ao Benin, os agudás. Essa última entrevista serviu de base para a elaboração do artigo "Milton Guran, a fotografia em três tempos” (Mauad, 2009), publicado em 2009. Assim, foi esse texto publicado que acabou por atuar como base narrativa para a montagem da sequência visual.

$\mathrm{O}$ projeto visual inicial para dar corpo à tentativa de transmitir uma trajetória de vida, em três tempos diferenciados construídos com recortes de entrevistas realizadas num tempo presente, foi pensado da seguinte forma: imagens recentes de Milton Guran, em close, falando a uma plateia, posicionadas de um lado da tela, suprimindo o áudio original e sobre elas aplicada parcialmente opacidade. Parte da tela negra revelava, em fade, as fotografias do tempo que o áudio demarcava. A tela apresentava em quase todos os momentos o criador e a criatura, que ora se confundiam através de fusões e controles da opacidade das imagens. Entretanto, depois de ter sido apresentado este material audiovisual a Milton Guran, a concepção visual foi alterada. Na

2 Para uma perspectiva completa dessa tipologia, acessar: www.historia.uff.br/labhoi.

3 Financiado pelo CNPq com bolsa de produtividade 2005-2008. As entrevistas realizadas no âmbito desse projeto foram tratadas segundo os protocolos de arquivamento adotados pelo LABHOI, que incluem: duplicação do áudio na base de dados sonoros; composição da ficha-sumário com o resumo da entrevista, acompanhada da identificação do entrevistado, equipe de entrevistadores, local, data e duração da entrevista; e transcrição completa do áudio. 
sua avaliação, Guran destacou que os movimentos de câmera, bem como os enquadramentos e as opacidades aplicadas em algumas fotografias, não permitiam a sua apreensão integral pelo expectador, comprometendo a leitura visual da imagem criada por ele.

Em face dessa crítica, buscamos uma resposta à questão colocada por Guran, não somente o sujeito-agente das memórias, mas o autor das imagens que detonaram o processo de rememoração. Assim decidiu-se por se manter a integridade total das fotografias que compunham a série visual, e delimitamos um tempo médio em que elas permaneceriam estáticas, em sua primeira aparição, garantindo com isso o momento de contemplação pelo expectador. A imagem de Milton Guran que aparecia em todo o vídeo, ora em primeiro e ora em segundo plano, foi suprimida. Dois trechos de áudio correspondentes a duas fotografias, $O$ retorno de Arraes e Mães militante na luta pela anistia (Tempo 1-5'34" a 7'50"), antes selecionados para possíveis extras, foram incorporados à narrativa do primeiro bloco; o comentário da fotografia do soldado na Esplanada dos Ministérios foi trocado por outro, e, para cada tempo, mais três fotografias foram adicionadas ao início de seus respectivos blocos.

Em resumo, na edição final, o texto videográfico Milton Guran em três tempos apresenta uma introdução com imagens recolhidas aleatoriamente de Milton Guran em uma palestra sobrepostas a um trecho curto de áudio, seguida de seus respectivos três tempos divididos em três blocos como originalmente se apresentam no texto publicado. Apoia-se numa série visual composta por fotografias com enquadramento no centro da tela, por tempo inicial médio de cinco segundos, duração na qual a imagem estática pode ser devidamente contemplada na sua integridade original. Movimentos foram adicionados à edição das imagens procurando demonstrar detalhes e enfatizar com comentários do áudio. Nenhum efeito de correção de cor, ajuste de brilho, etc. foi aplicado nas fotografias. O áudio foi editado mantendo-se os trechos que preservaram o sentido original da construção do pensamento, evidenciado no processo de entrevista com Guran.

A título de conclusão, vale indicar que as condições para a produção do texto videográfico são variadas. Em primeiro lugar, variam de acordo com as modalidades de parceria que se estabelece entre os profissionais de cinema e os historiadores acadêmicos. Nesse campo, se coloca a questão da disputa pelo sentido produzido no âmbito de uma competência elaborada na construção da linguagem fílmica, por um lado, e da tradição do texto historiográfico, por outro. O resultado desse embate, em geral, é a produção de um texto 
criativo onde as competências de cada campo interagem na busca de uma nova forma de comunicar o sentido histórico.

Em segundo lugar, variam de acordo com as condições nas quais a construção da autoridade compartilhada se estabelece. Na experiência com Milton Guran ressalta-se o fato de que estamos tratando de um profissional que molda visualmente a sua forma de compreender e fornecer sentido ao mundo sensível. Daí a necessidade de incorporarmos o seu olhar à forma como ele narrou a sua trajetória.

Temos, portanto, a produção tanto de uma nova forma de comunicar os resultados da pesquisa histórica, apoiada nos recursos das novas tecnologias; como, também, de exercitar um tipo de operação histórica, associada às novas demandas epistemológica do tempo presente, nas quais os lugares, os sujeitos e os discursos se redefinem na elaboração de uma nova escritura da história - um neologismo, talvez, mas que permite associar linguagem de vídeo à historiografia, para um público cada vez mais variado e ampliado.

Ver o vídeo Milton Guran em três tempos:

Parte 1 - http://www.youtube.com/watch?v=T2bup15Nz4w

Parte 2 - http://www.youtube.com/watch?v=lYE2wK9YmTY

\section{Referências}

FRISCH, M. A shared authority: essays on the craft and meaning of oral and public history. New York: State University of New York Press, 1990.

MAUAD, A. M. Milton Guran, a fotografia em três tempos. Studium, n. 28, Inverno 2009. Disponível em: <http://www.studium.iar.unicamp.br/28/01.html>. Acesso em: 10 nov. 2010.

Resumo: O artigo aborda os usos das fontes orais e visuais, compreendidas como fontes de memória, na produção do conhecimento histórico, atribuindo-lhe uma dimensão intertextual. Introduz o conceito de escrita videográfica, como base metodológica para a produção de textos históricos que considerem o cruzamento entre palavras e imagens. Finalmente, apresenta como exemplo dessa estratégia metodológica, a fatura do texto videográfico Milton Guran em três tempos (LABHOI, 2010, 24min).

Palavras-chave: fontes orais, fontes visuais, memória, metodologia histórica. 
Sources of Memory and the concept of videographic writing: considerations about the videographic text Milton Guran em três tempos (LABHOI, 2010)

\begin{abstract}
The article deals with the uses of oral and visual sources, understood as sources of memory, for the production of historical knowledge, assigning it an intertextual dimension. It also introduces the concept of videographic writing, as a methodological basis for the production of historical texts, which considers the crossing between words and images. Finally, it presents as an example of this methodological strategy, the making off the videographic text Milton Guran em três tempos (LABHOI, 2010, 24min).
\end{abstract}

Keywords: oral sources, visual sources, memory, historical methodology.

Recebido em 12/12/2010

Aprovado em 10/01/2011 